\title{
Treatment of Various Post-Inflammatory Hyperpigmentation with Low Fluence Q-Switched Nd:YAG Laser: In Asian Patients
}

\section{Sangeun Kim*}

Department of Dermatology, Yonsei-Zium Dermatologic clinic, Seoul, Korea

*Corresponding author: Sangeun Kim, Department of Dermatology, Yonsei-Zium dermatologic clinic, Seoul, Korea, Tel: 82-02-333-0606; Fax: 82-02-333-7585; E-mail: expo9406@naver.com

Rec date: June 18, 2015; Acc date: August 25, 2015; Pub date: Sepetember 11, 2015

Copyright: (c) $2015 \mathrm{Kim} \mathrm{S}$. This is an open-access article distributed under the terms of the Creative Commons Attribution License, which permits unrestricted use, distribution, and reproduction in any medium, provided the original author and source are credited.

\section{Introduction}

Post inflammatory hyperpigmentation (PIH) due to various skin conditions commonly occurs in Fitzpatrick skin types IV to VI and can have a considerable impact on quality of life. The sequelae in terms of pigmentation are often the main reason for consulting a dermatologist.

\section{PIH after Various Procedure}

Post inflammatory hyperpigmentation (PIH) developing after cosmetic procedures, such as chemical peeling and laser therapies, are always a concern, especially in Asians. Some cases of PIH tend to be spontaneously regressed; however, certain forms of PIH need to be treated with several therapeutic attempts, including bleaching creams, several kinds of Q-switched lasers, and erbium-doped fractional photothermolysis system, with various treatment outcomes. A 1064 nm Q-switched Nd:YAG laser with low-fluence therapy is easily applicable, and the therapeutic trial in our case was revealed to have minimal downtime without post-therapy bleeding or crust formation; the post-therapy erythema spontaneously resolved within a few hours. The $1064 \mathrm{~nm}$ Q-switched Nd:YAG laser with low-fluence treatment should be considered in the treatment of PIH caused by procedures like laser surgery and chemical peeling in Asian patients.

\section{PIH after Keratosis Pilaris and Atopic Dermatitis}

Treatment in most cases of keratosis pilaris requires simple reassurance and general skin care recommendations. Many Asian patients find lesions cosmetically unappealing due to pigmented keratosis pilaris. In the treatment of keratosis pilaris, the use of QSNY laser can be helpful for achieve better cosmetic appearance because it could improve pigmentation.
A novel combined photoacoustic/photothermal QSNY laser can be used for keratosis pilaris with brown pigmentation.

We used a high pulse rate $(10 \mathrm{~Hz})$ QSNY laser for the treatment of pigmentation accompanied with keratosis pilaris. Patients underwent five-weekly treatments using a QSNY at $1064 \mathrm{~nm}$, which is thought to produce both a photothermal and a photoacoustic effect in tissue (RevLite, HOYA ConBio, Freemont, CA, USA). No anesthesia was necessary prior to treatment.

\section{PIH after Acne Vulgaris}

Post inflammatory hyperpigmentation (PIH) due to facial acne commonly occurs in Fitzpatrick skin types IV to VI and can have a considerable impact on quality of life [1-3].

$1064 \mathrm{~nm}$ QSNY laser treatment was found to be very effective at treating PIH and also have additional effects on comedonal extraction, topical benzoyl peroxide and intralesional injection for concomitant acne lesions in Asian patients. In addition, this method is effective in producing an additive effect, resulting in a more refreshed appearance, even skin tone, smoother texture, tightening and decreased pore size.

\section{References}

1. Kim S, Cho K (2010) Treatment of Facial Postinflammatory Hyperpigmentation with Facial Acne in Asian Patients Using a QSwitched Neodymium-Doped Yttrium Aluminum Garnet Laser. Dermatol Surg 36: 1-7.

2. Kim S, Cho K (2010) Treatment of procedure-related postinflammatory hyperpigmentation using 1064-nm Q-switched Nd:YAG laser with low fluence in Asian patients: report of five cases. Journal of Cosmetic Dermatology 9: 302-306.

3. Kim S (2011) Treatment of pigmented keratosis pilaris in Asian patients with a novel Q-switched Nd:YAG laser. J Cosmet Laser Ther 3: 120-122. 